The War has unfortunately interfered with my own experiments, but the following observations seem worth recording.

In 1942 , I stated that "captive stoats have two moults". Since then I have found two specimens which moulted twice during the winter. It is inadvisable to handle these animals frequently as some risk of injury to themselves is always involved. It is, therefore, very easy to overlook the first winter (or autumn) moult, which is from brown to brown, and indeed it seems probable that this oversight has occurred where other specimens are concerned. I had previously noted ${ }^{1}$ that in my captive stoats the white pelage was carried for three to four months only, but that judging from museum skins, wild stoats in Scotland remained white for much longer periods. In the case of the former a colour change was involved in only one winter pelage; but it is possible that two successive moults may be white under the conditions prevailing in Scotland. Bissonnette found that his captive Bonaparte weasels could be induced to moult from white to white.

Although considerable variation occurs between individuals, and also from year to year in the same specimen, the order of the moult is similar to that described by Bissonnette for both species of weasels. Winter moults begin on the underneath of the belly and sweep up the legs, tail (distal portion first) and sides of the body. The top of the head and a narrow line down the neck and centre of the back are the last portions to turn white. In the spring moults the process is reversed, and the brown hairs grow in first on the head and along the middle of the back. The tip of the tail, of course, remains black throughout.

Even if the winter moult does not involve whitening, the brown coat is slightly lighter in colour than the summer coat. The hairs on the belly are also less strongly tinged with yellow, although not pure white.

Experimental reduction of daylight was carried out with five captive stoats. It was found that by sudden or gradual shortening of the hours of daylight, additional moults could be induced in the spring and summer, but none of these moults involved a colour change. In one male stoat only, a few white hairs appeared on the feet and legs. This specimen had never previously changed colour. Afterwards it retained these white hairs throughout all moults over a period of two years.

Stoats which were subjected to gradual but drastic light reductions during the critical periods of the winter moults also did not change colour. One of the stoats in question had made a partial change to white in each of the two previous winters when exposed, during a period of sixty-three days, to thirty-four and forty-four days of temperatures below $32^{\circ} \mathrm{F}$. However, this stoat did not change colour at all under warmer conditions, despite curtailment of the hours of daylight. It was subjected to only twelve days of temperatures below $32^{\circ} \mathrm{F}$. The increased hours of darkness commenced on September 21 and on December 21 culminated in a three-week period, in which five hours of daylight alternated with thirty-six hours of darkness.

It will thus be seen that with regard to whitening of the pelage, $M$. erminea is far less susceptible than $M$. cicognanii to the effect of light reduction alone. This factor apparently plays a subsidiary part in the colour change of the British species. It does seem likely, however, as Prof. Bissonnette suggests, that reduction of temperature involves a change of habit which brings about a natural reduction of the light cycle and perhaps loss of activity, and that these factors play a complementary role in producing both moult and colour change. It would be extremely interesting to know if the New York weasel $(M$. frenata) could be induced to whiten if subjected to low temperatures in addition to reduced hours of daylight which induce only a moult to paler brown. It seems clear that the response to the different factors governing pelage changes varies greatly, not only from individual to individual and at different times of the individual's life, but also from species to species.

Ashton Wold, Peterborough.

Mrriam Rothschird. June 11.

${ }^{1}$ Rothschild, M., Nature, 149, 78 (1942)

2 Bissonnette, T. H., Trans. New York Acad. Sci., 5, Ser. II, No. 3 , 43 (1943).

\section{An Unusual Host for a Polypore}

IN December 1943 through the kindness of Dr. K. P. Biswas, superintendent of the Lloyd Botanical Gardens of Darjeeling, I obtained a

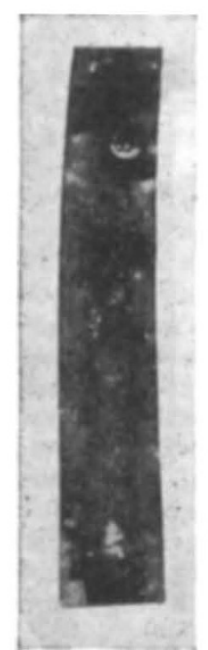

Fra. 1. FRUCTIFICATION O $P$. sanguineus. few specimens of green leaflets of a Macrozamia sp. from the Darjeeling garden bearing tiny fructifications of Polystictus sanguineus (Linn.) May. on their back surface (see accompanying illustration). Sections of the fructifications showed normal basidia and white and oval spores (4-6 $\times 3-4$ mic.) of $P$. sanguineus. In sections of leaflets under the microscope partial disintegration of chloroplastids at places and formation of tannin drops were detected though the leaflets were quite green to the naked eye.

So far, I have not come across any mention of a polypore fruiting on green leaves of higher plants-an apparent parasitic habit; by correspondence (March 9, 1944) with Dr. L. O. Overholts of the Pennsylvania State College I learn that he also has no such experience. Thus, this may be recorded as the smallest polypore yet known.

S. R. BosE.

Botanical Laboratory,

Carmichael Medical College, Calcutta. June 12.

\section{The Pisiform Bone}

Prof. H. A. Harris's ${ }^{1}$ rediscovery of the secondary centre of ossification in the pisiform confirms the work of Retterer ${ }^{2}$, who found it in cat, dog and rabbit, and Sieglbauer ${ }^{3}$, who found it in chimpanzee, gorilla, Tarsius, Stenops and Macacus. But his conclusions from its "hitherto unsuspected existence" are scarcely justifiable, for there is no reason for believing that secondary centres are a prerogative of one type of skeletal element. His letter does raise the question of what criteria can be used to determine whether a bone is a sesamoid.

Sesamoids appear where tendons of muscles turn over bony prominences, and have one surface cartilage-covered to glide over the prominence, separated by a synovial cavity, while the other 